
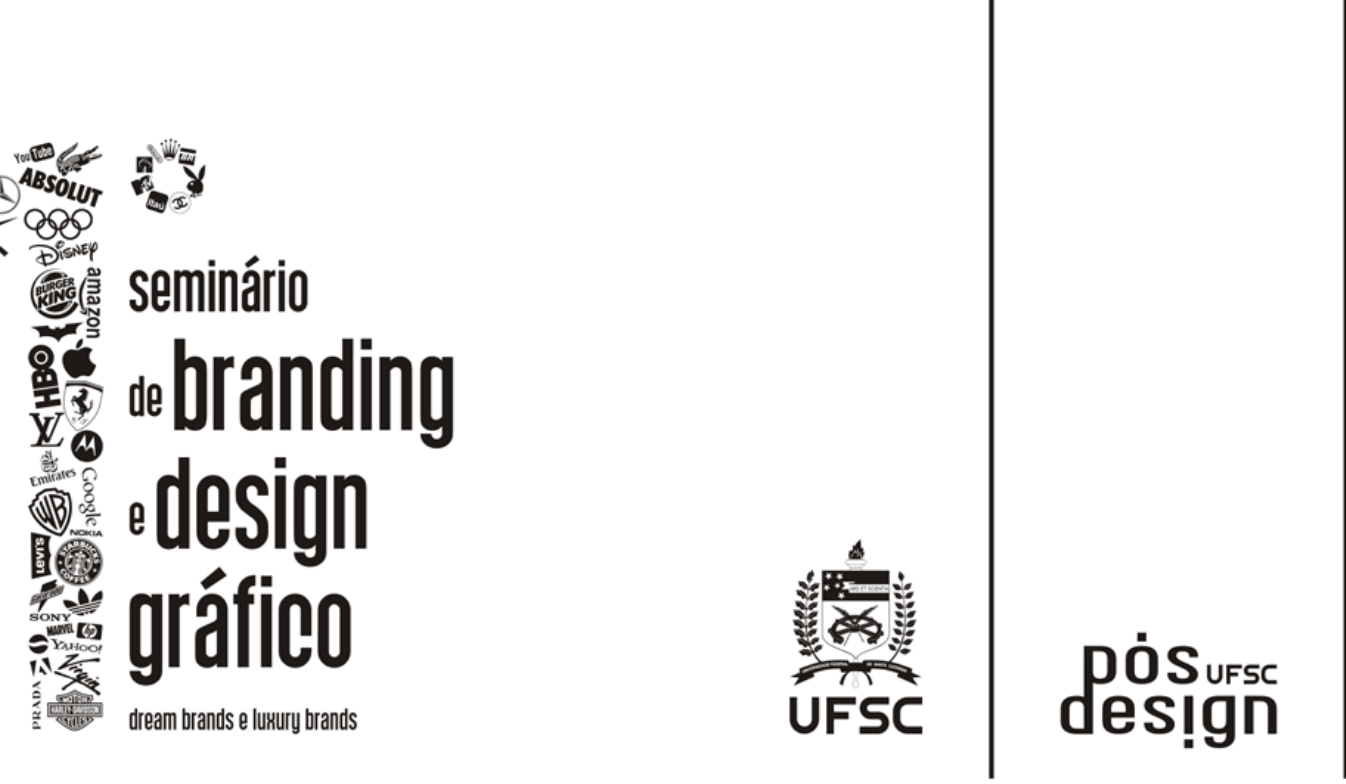

LOGO

\title{
O Principado de Mônaco como marca territorial de luxo
}

Monaco's territorial brand

Silva, Natacha Pontes da; Mestranda do PósDesign; Universidade Federal de Santa Catarina natachapontes@gmail.com

\section{Resumo}

A marca associada a um território se constitui pelo acervo simbólico em torno de suas expressões naturais e culturais. O nome e os símbolos que representam um território além de cumprir as funções de identificação e diferenciação, auxiliam na promoção de sua imagem. Este artigo apresenta a marca territorial de Mônaco e os elementos visuais que legitimam sua imagem com atributos de luxo e beleza. A história, o conceito de luxo e suas expressões são relacionados à realeza e, no contexto de branding territorial, o país de Mônaco também é diretamente relacionado com a realeza, indicando-lhe o atributo de marca territorial de luxo.

Palavras Chave: Branding de Luxo; Imagem de Marca; Marca Territorial.

\section{Abstract}

The brand related to a territory is made up of its symbolic cultural heritage based on its natural and cultural expressions. Therefore, the names and symbols which represent a territory not only carry the function of identifying and stating its differences, but also of promoting its image. This study presents Monaco's territorial brand and the visual elements which highlight and legitimate its luxury and beauty.

Keywords: territorial brand; visual identity ; luxury. 


\section{Introdução: O Luxo como valor simbólico}

O objetivo deste artigo é indicar que o caráter simbólico estabelece o luxo como atributo de marca, sendo que os objetos, as pessoas ou os lugares capazes de expressar este conceito ou este atributo simbólico passam a ser percebidos como sinais de expressão do luxo, como parte de sua imagem ou de sua marca. Para tanto, propõe o Principado de Mônaco como um exemplo de marca território, que é capaz de expressar status e glamour, compondo o conceito de luxo, como é indicado a seguir.

Esse intento se justifica porque as marcas são entidades duplas, reunindo sinais, coisas tangíveis e perceptíveis, e emoções ou conceitos, que são coisas intangíveis ou imperceptíveis por si mesmas. Portanto, uma marca sem um processo de significação é só um sinal. Mas um sinal relacionado a sentimentos ou idéias é símbolo. Todas as marcas são símbolos e as marcas de luxo são compostas por sinais capazes de expressar o luxo, que é um valor simbólico.

Para compreender o luxo na atualidade é necessário recorrer às idéias e conhecimentos propostos por Lipovetsky e Roux no texto "O luxo eterno: da idade do sagrado ao tempo das marcas" (2005), porque esses autores conceituam e estudam o luxo ao longo da história, a partir da cultura de consumo, como composta na atualidade. Portanto, os dados e idéias deste item são apresentados a seguir, com base no texto dos autores indicados, para os quais o luxo, apesar de estar associado ao materialismo, surge na sociedade como algo ligado à espiritualidade, antecedendo à fabricação e à acumulação de bens valiosos, que são apenas um dos sinais possíveis para sua expressão.

\footnotetext{
O luxo não começou com a fabricação de bens de preço elevado, mas com o espírito de dispêndio: este precedeu o entesouramento das coisas raras. Antes de ser uma marca da civilização material, o luxo foi um fenômeno de cultura, uma atitude mental que se pode tomar por uma característica do humano - social afirmando seu poder de transcendência, sua não-animalidade. (LIPOVETSKY; ROUX, 2005, p. 22)
}

$\mathrm{Na}$ sociedade primitiva os bens preciosos não utilitários já existiam e eram cobiçados. Porém, a forma primitiva de luxo não se caracterizava pela posse e acumulação de bens, mas pela dádiva obtida na troca cerimonial, na munificência e na distribuição de objetos de valor. Nesse período, a dádiva suntuária tinha por objetivo conferir honras aos deuses em troca de sua proteção e benevolência espiritual, de tal modo que os bens mais preciosos assumem seu caráter religioso, cósmico metafísico e mágico.

Foi com o surgimento do estado e com a divisão da sociedade em classes que o luxo liga-se aos princípios de distinção. Porém o luxo está associado, num primeiro momento, à idéia de inalterabilidade e de permanência. No Egito antigo os faraós edificavam as arquiteturas funerárias de modo a garantir sua opulência na eternidade. "O fausto não é objeto ou imagem a contemplar, é o instrumento mágico que facilita o acesso à vida eterna." (LIPOVETSKY; ROUX, 2005, p. 32)

A partir da idade média e da renascença, o luxo no ocidente adquire seu sentido cultural. Com o mecenato aos artistas, suas obras de arte tornam-se objetos de grande valor e prestígio perante a elite. O luxo laicizou-se frente a valorização da vida terrena pelo interesse do homem 
em se tornar renomado e reconhecido, estabelecendo uma relação mais estética com os bens dispendiosos.

No século XIV surgem dois fenômenos que marcam o luxo moderno: o primeiro centrado no humanismo, baseava-se na valorização dos objetos da antiguidade clássica como estátuas, moedas, vasos e medalhas; o segundo, e em oposição ao primeiro, é centrado no culto ao que é novo, efêmero e frívolo. Tal fato contribui para a valorização dos artigos de moda, incentivada por uma sociedade cada vez mais individualista. O luxo, então, personaliza-se, trazendo consigo o nome do costureiro ou da casa de auto-costura.

Com o advento da mecanização e a crescente industrialização, a produção de bens em série conduz ao aparecimento de um semiluxo ou de um falso luxo, de preço mais baixo e acessível à classe média, os objetos de luxo tornam-se cada vez mais democratizados.

O luxo na pós-modernidade é globalizado e financeirizado. As marcas de luxo intensificam a reputação dos grandes grupos comerciais "O luxo é sempre o elemento de diferenciação social, mas funciona cada vez melhor, como ferramenta de management das marcas para o grande público, uma vez que o prestígio do top de linha repercute no conjunto dos modelos." (LIPOVETSKY; ROUX, 2005, p. 49). É neste momento que nos deparamos com o luxo marketing, condizente com a lógica do mercado.

Diante de uma atitude neo-individualista, na qual as normas estabelecidas pelas instituições sociais não são mais tomadas como referência, os indivíduos não se preocupam em retratar exclusivamente uma imagem para o outro, mas visam constituir uma boa imagem para si. É a vez da valorização do sujeito. Surge o luxo experiencial e sensitivo, o luxo emocional. Além dos elementos que devem singularizar e legitimar as marcas de luxo, estas devem salientar os benefícios emocionais proporcionados pela experiência, para que possam justificar o seu alto valor.

$\mathrm{Na}$ trajetória da história da humanidade, é recursivo e conclusivo o caráter simbólico como determinante do luxo. O luxo pode ser representado por diferentes coisas, um objeto, um nome, uma marca ou um lugar. Estes bens são dotados por aspectos simbólicos, imateriais, que necessitam ser qualificado por um grupo restrito segundo códigos estabelecidos em uma época. Esses aspectos simbólicos são cedidos àqueles que detêm o privilégio de possuí-los ou usufruílos, quer seja por gozarem de privilégios mágicos, religiosos, políticos ou econômicos, assim, o que se torna recorrente, visto no decorrer da história do luxo, é sua função de legitimação social. 


\section{A Marca de Mônaco como território de luxo}

A marca associada a um território é constituída pelo acervo simbólico em torno das expressões naturais e culturais de uma região. Diante disso, branding territorial é determinado pela gestão da imagem de marca territorial e remete à construção de um conjunto de imagens positivas diretamente relacionadas ao mesmo. O nome e os outros símbolos, como o brasão, as cores e a bandeira, além de cumprirem com as funções de identificação e de representação, devem promover sua imagem e atribuir notoriedade à região, porque os anunciantes da marca anseiam em obter o envolvimento dos públicos interno e externo, promovendo comportamentos de produção e consumo favoráveis ao desenvolvimento territorial (GAIO e GOUVEIA, 2007).

O Principado de Mônaco é considerado um microestado localizado na costa do mar Mediterrâneo, sul da França. A história de Mônaco é marcada por inúmeras ocupações de povos gregos, fenícios e romanos. Depois dessas sucessivas invasões, em 1191 o território passou a ser colônia de Gênova. Em 1297, a região foi concedida à família Grimaldi, que governa o principado ainda hoje. Todavia, durante a Revolução Francesa, Mônaco foi incorporado à França e, somente no Congresso de Viena, em 1815, é que sua independência foi parcialmente restaurada.

O percurso da marca institucional e empresarial do principado, ligada ao turismo de luxo, começa em 1863, quando foi inaugurado o "Cassino de Monte Carlo" com a finalidade de atrair a alta sociedade internacional e contribuir para o progresso econômico local. Em 1918, França e Mônaco estabelecem um novo tratado que determina a proteção francesa, compondo a política e a economia locais, em concordância com as da França. Para cumprir o tratado, a família Grimaldi teve que perpetuar sua descendência, evitando que o principado fosse incorporado à França. A linhagem dos Grimaldi foi interrompida no final do século XIX, quando o príncipe Louis II governava o país. Para resolver a questão Louis II reconhece sua filha ilegítima, Louise-Juliette, e esta abdica ao governo em favor de seu filho, o príncipe Rainier III.

Em 1956, o príncipe Rainier casou-se com a atriz norte-americana Grace Kelly, reunindo o simbolismo da realeza aristocrática à mitologia moderna do cinema americano. $\mathrm{O}$ encantamento de "Cinderela" se realizou, juntamente com a emancipação e a atualização do principado no universo da mídia de consumo, compondo uma marca glamourosa e inrresistível no imaginário mundial. O casamento gerou três filhos: Caroline, Stéphanie e o príncipe Albert II, que é o sucessor de seu pai, Rainier III.

Em grande parte, a economia do principado é movimentada pelo setor imobiliário e hoteleiro, característicos de uma região turística. Além do clima mediterrânico e da vegetação exuberante, o principado simboliza glamour, status e diversão, promovendo o turismo de luxo.

A permanência da monarquia, cujo governo continua a ser regido por príncipes e princesas em plena pós-modernidade, confere a Mônaco um alto valor simbólico, especialmente para os ricos em busca do status, que é atribuído à nobreza e que permanece em Mônaco, perpetuando-se na descendência da família Grimaldi. Mesmo frente às transformações políticas e econômicas vividas por demais países, Mônaco preserva sua linhagem real e assim eterniza o glamour e o luxo de outrora. Turistas do mundo inteiro são atraídos pela singularidade e prestígio associados à imagem de luxo de Mônaco. 


\section{Elementos de Identidade Visual}

Os elementos visuais utilizados para compor os símbolos de marca do território ressaltam a permanência da descendência real. A imagem de François Grimaldi (fig. 1) é um símbolo que recorre ao passado medieval, recuperando o momento de sua conquista do principado, como um mito de origem que é necessário à composição das marcas. A imagem serve de fonte para os elementos gráficos e as cores, que são utilizadas na composição das marcas gráficas do principado de Mônaco, seja o brasão da realeza (fig. 2) ou a marca do território (fig. 3). Os elementos da vestimenta são reproduzidos nos demais símbolos, que constituem a identidade visual da marca Mônaco (fig. 2 e 3).

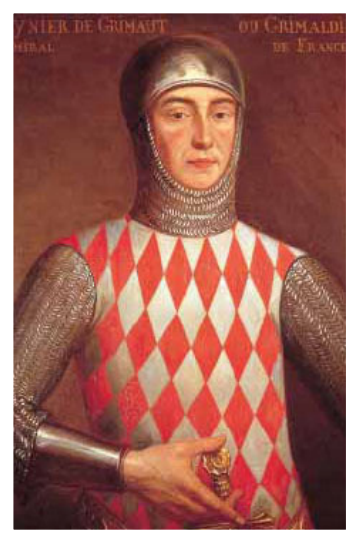

Figura 1: Imagem de François Grimaldi

Durante as batalhas, as armaduras eram necessárias para defesa militar, porém as mesmas faziam com que os grupos ficassem praticamente irreconhecíveis. Para se distinguir frente ao grupo adversário, foram adotados elementos visuais que pudessem ser visíveis a longas distâncias. As formas e as cores, que juntamente com os penachos, estandartes e bandeiras constituíam um código de identificação e reconhecimento bélico. A indumentária de François Grimaldi (fig. 1) faz referência aos apetrechos de combate e à identificação dos exércitos, apresentando uma seqüência de formas geométrica simples composta por losangos e por um intenso contraste entre as cores vermelho e branco, de forte impacto visual o que facilitava o reconhecimento durante os confrontos. 


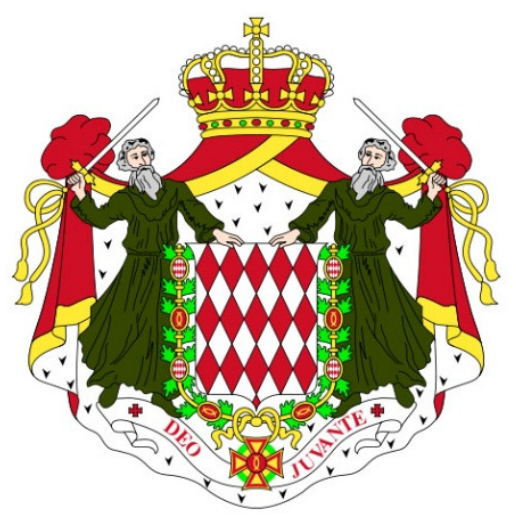

Figura 2: Brasão de Armas de Mônaco

Os brasões, de acordo Costa (2008, p. 56), foram inicialmente signos militares, mas com o passar do tempo se transformaram em signos que representaram personalidades, famílias, dinastias, propriedades e direitos. "Esses símbolos gráficos pertencem àqueles que os utilizam (os identificam) e a seus herdeiros." As formas dos brasões estavam relacionadas à origem geográfica ou a um período histórico. A configuração presente no escudo central do brasão da família Grimaldi (fig. 2) está associada a sua origem francesa. A mesma composição de losangos e cores se faz presente no símbolo heráldico de modo a identificar a sua linhagem.

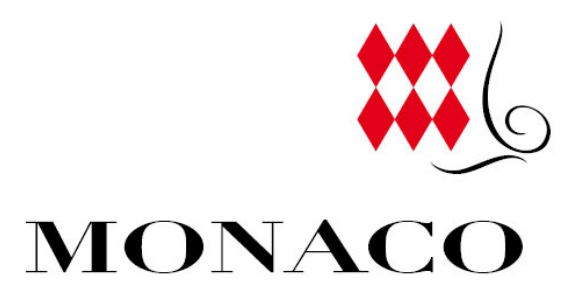

Figure 3: símbolo e logotipo de Mônaco para a promoção do turismo

O logotipo e o símbolo gráfico (fig. 3) que representam a marca território de Mônaco preservam os mesmos elementos visuais que identificam a família real. O uso desses elementos corrobora para conceder à marca os atributos associados à realeza. Assim sendo, o valor simbólico do luxo, sua imaterialidade, presente na origem monárquica é conferido ao território através de sua expressão visual. É como se os elementos gráficos pudessem estabelecer um elo, uma ligação entre os signos pertencentes áurea da nobreza e os signos que querem ser atribuídos ao território. 


\section{Considerações finais.}

A marca Mônaco representa um principado, no qual um grupo restrito, ainda hoje, goza dos poderes, dos privilégios e do status da realeza. Esse grupo composto por pessoas com nome, "Ranier", "Grace Kelly", "Caroline”, "Stéphanie”, "Albert", e sobrenome "Grimald”, é associado a uma longa tradição de glórias e riquezas, que também é relacionada a um pequeno território em termos de país, cujo clima agradável e a paisagem exuberante foram compostos com construções e objetos culturais de forte apelo simbólico. Além disso, a associação desse patrimônio ao mundo do cinema e dos cassinos reuniu status e glamour como símbolos dessas pessoas e desse território associando humanidade e fantasia, por meio do luxo determinado pela riqueza material e simbólica, que envolve a realeza, os cassinos e o cinema comercial.

A permanência do governo monárquico corrobora para conceder ao principado um sentido único e imaterial. Todavia, desde da década de 1950, a realeza de Mônaco também coquistou o glamour do mundo das artes e dos espetáculos, passando a simbolizar o status da realeza, o glamour das divas e o alto custo que requer a conquista desses valores, como elementos para a composição de uma marca territorial de luxo.

\section{Referências}

LIPOVETSKY, G.; ROUX, E. O luxo eterno: da idade do sagrado ao tempo das marcas. São Paulo: Companhia das Letras, 2005.

COSTA, Joan. A imagem da marca. Um fenômeno social. São Paulo: Edições Rosari, 2008.

GAIO, S.; GOUVEIA, L. B. O Branding Territorial: uma abordagem mercadológica à Cidade. Revista A Obra Nasce. Edições UFP, p. 27-36, 2007.

THE PRINCIPALITY OF MONACO. Historia, instituciones, economia y relaciones internacionales. Disponível em: http://www.visitmonaco.com/pdf/DTCMONACO/Brochures/Espagnol/Brochure_Histoire_ESP.p df/: Acesso em: 22 set. 2008 